\title{
Kinerja Soil Stabilizer Polymer Termoset Terhadap Sifat Fisik dan Sifat Mekanis Tanah Pasir sebagai Material Jalan
}

\author{
Sukatik* \\ Sri Nita* \\ Roni Tri Putra* \\ Ratih Paramitha** \\ *Politeknik Negeri Padang \\ **Sekolah Tinggi Ilmu Kesehatan Nurliana Medan
}

\begin{abstract}
Abstrak
Soil stabilizer polymer hasil campuran lateks polyester tak jenuh Yukalac 157 BQTN-EX dengan lateks pekat karet alam (LPKA), disebut soil stabilizer termoset (SSTS). Campuran ini homogen pada perbandingan 90/10 dan stabil hingga hari ke 28 penyimpanan, dapat digunakan sebagai perekat tanah pasir untuk meningkatkan sifat kekuatannya. Melalui berinteraksi gugus polar pada polester dengan partikel tanah pasir diprediksi dapat membentuk komposit yang memiliki sifat mekanis yang tangguh sebagai material jalan. Hasil uji mekanis komposit tanah yang distabilkan dengan SSTS meningkat hingga penambahan SSTS 35\%. Kuat tekan meningkat hingga penambahan SSTS $25 \%$ dan menurun pada penambahan lebih tinggi - Daya serap air menurun dengan peningkatan jumlah SSTS. Hasil uji termal terdapat pergeseran puncak dari polyester, SSTS dan komposit campuran SSTS dengan tanah pasir.
\end{abstract}

Kata kunci : soil stabilizer, polyester,lateks pekat karet alam, sifat mekanis, material jalan. Email : sukatikwiryosentono@gmail.com 


\section{PENDAHULUAN}

Soil stabilizer polimer dapat digunakan untuk memperkuat struktur tanah, mengendalikan debu dan erosi tanah karena dapat berinteraksi dengan partikel-partikel tanah dan mengisi pori-pori antar partikel tanah, cepat mengering menjadi lapisan yang keras dan kenyal sehingga tanah menjadi padat dan stabil menyebabkan daya dukung meningkat. Bahan ini dapat digunakan pada areal parkir, proyek pembangunan waduk, jalan di lahan perkebunan dan daerah pemukiman, pada lereng bukit dan bahu jalan untuk mengendalikan erosi tanah (Management Practices Manual, Temporary Erision Management EC-8 SOIL BINDER, 2011).

- Penggunaan soil stabilizer polimer untuk perkerasan jalan sudah dilakukan oleh negara-negara maju seperti Jepang, Amerika Serikat, dan Eropa (Feldman, 1995). Malaysia dan Singapura juga telah menggunakan soil stabilizer polimer untuk stabilisasi jalan raya dan airport (Wu Dong, 2008). Christopher 2010 melaporkan bahwa Kanada memiliki sejarah penggunaan soil stabilizer polimer yang baik, dan baru-baru ini telah dilakukan percobaan penggunaan soil stabilizer polimer di Alberta,
Saskatchewan dan Prince Edward Island untuk stabilisasi tanah pada konstruksi jalan raya.

Penelitian di bidang soil stabilizer polimer ini sudah lama dilakukan.. Lateks polimer sudah digunakan untuk melapisi permukaan jalan setapak dengan ketebalan bahan lebih dari 2 inci dapat memberi hasil yang baik dan dapat bertahan selama beberapa tahun (Roger Bergnann et al, 2000). Emulsi polymer dapat digunakan untuk meningkatkan kekuatan tanah pada kondisi basah (Santoni et al 2003), emulsi Polyvinyl Asetat (PVA) dapat digunakan untuk meningkatkan nilai California Bearing Ratio (CBR) tanah Sub-Grade pada konstruksi jalan (K. Moto et al, 2004), penggunaan PVA untuk melapisi jalan dan dapat memperbaiki terjadinya alur akibat beban lalu lintas (Valencia et al., 2007). A.Marco da Silva et al, 2010, menggunakan poliakrilamida (PAM) dalam penelitiannya untuk mengontrol erosi tanah dan untuk mengurangi dampak proses degradasi tanah. Sameer Vyas et al, (2011) menggunakan berbagai jenis polimer untuk stabilisasi tanah dispersif. Para peneliti ini telah menggunakan berbagai jenis polimer baik polimer alam maupun polimer sintetis, 
namun pada aplikasi sebagai soil stabilizer relative masih menggunakan satu jenis polimer. Maka dalam hal ini perlu dikembangkan campuran beberapa polimer sebagai soil stabilizer.

Disisi lain polyester tak jenuh Yukalac 157 BQTN-EX sebagai polimer termoset, merupakan perekat yang baik, memiliki sifat mekanis yang baik, sering digunakan sebagai bahan perekat pada pembuatan papan partikel karena dapat berinteraksi dengan baik dan kompatibel dalam campuran bahan yang mengandung gugus polar pada rantainya (Pasaribu R, 2006; Ratri Pantoro, 2007). Interaksi antara gugus polar polyester dengan partikel tanah pasir terjadi Polimer ini dapat dijadikan emulsi (lateks) dan berpotensi sebagai bahan soil stabilizer.

Salah satu bahan alam hasil utama Indonesia yang berpotensi sebagai bahan soil stabilizer adalah latek pekat karet alam (LPKA). Indonesia merupakan negara penghasil karet alam terbesar kedua setelah Thailand. Pada tahun 2000 mencapai 1,56 juta ton, sementara pada thun 2005 telah mencapai 2,3 juta ton (Kompas 2006). namun konsumsi karet domestik masih relatif rendah, pada tahun 2005 negara berkembang termasuk Indonesia hanya 2,9 juta ton, sementara AS 1,3 juta ton, China 2,08 juta ton (International Rubber Study Group = IRSG), sedangkan produksi karet dunia telah melebihi permintaan negara konsumen yang mengakibatkan harga karet alam cenderung berfluktuasi.

Dalam tulisan ini dijelaskan pencampuran lateks polyester tak jenuh Yukalac 157 BQTN-EX dengan LPKA dan dijadikan sebagai soil stabilizer. Gugus polar polyester dengan agregat tanah pasir, dapat berinteraksi membentuk campuran tanah yang memiliki ikatan yang kuat yang memiliki daya dukung yang baik dengan karakteristik seperti yang diharapkan sebagai material jalan, lapisan permukaan penahan erosi, dinding waduk maupun arena parkir. Ilustrasi mekanisme proses crossling polyester dan monomer styrene dengan bantuan katalis MEKP.

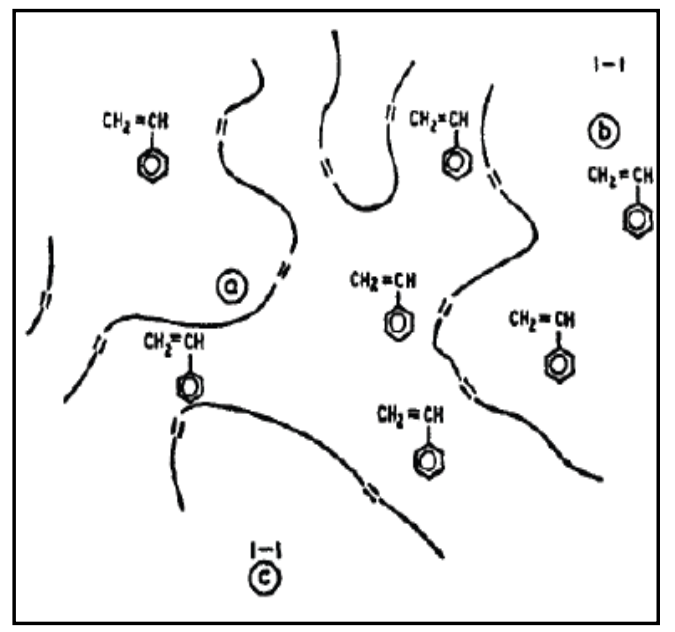


Gambar 1. Polyester tak jenuh.

Keterangan :

a. Polyester tak jenuh dengan BM rendah

b. Molekul larutan reaktif (styrena)

c. Molekul inisiator (katalis).

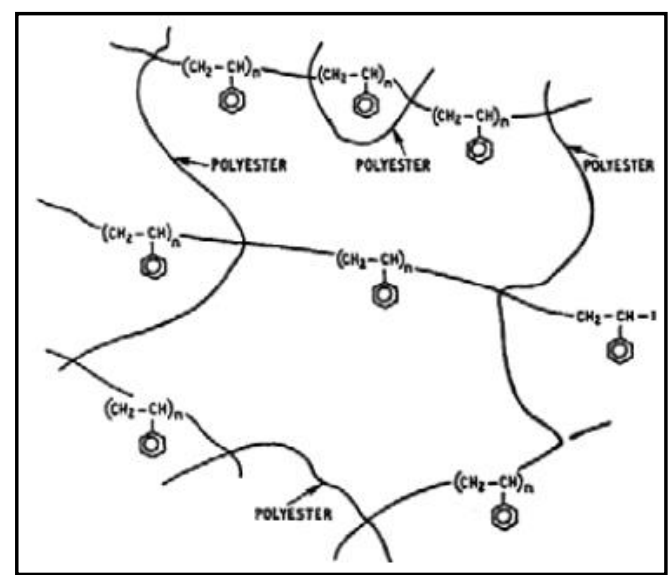

Gambar 2. Struktur polyester jenuh sesudah

waktu curing menggunakan

inisiator MEKP..

\section{Interaksi antara Poliester Tak Jenuh} dengan Partikel Tanah Pasir.

Campuran lateks polyester dengan LPKA yang disebut SSTS akan digunakan untuk stabilisasi agregat tanah pasir. Interaksi antara SSTS dan partikel tanah pair terjadi melalui gugus polar yang dimiliki rantai polyester dengan $\mathrm{SiO}$ pada tanah pasir, dengan interaksi ini diharapkan dapat meningkatkan sifat mekanis, sifat fisik dan ketahanan termal tanah pasir yang telah distabilkan dengan campuran lateks polyester dengan LPKA. Adapun prediksi interaksi polyester dengan tanah pasir melalui gugus polar yang terdapat pada partikel pasir dan matriks polyester dapat diprediksikan seperti gambar dibawah ini.

\section{Interaksi antara Poliester Tak Jenuh dengan Partikel Tanah Pasir.}

Campuran lateks polyester dengan LPKA yang disebut SSTS akan digunakan untuk stabilisasi agregat tanah pasir. Interaksi antara SSTS dan partikel tanah pair terjadi melalui gugus polar yang dimiliki rantai polyester dengan $\mathrm{SiO}$ pada tanah pasir, dengan interaksi ini diharapkan dapat meningkatkan sifat mekanis, sifat fisik dan ketahanan termal tanah pasir yang telah distabilkan dengan campuran lateks polyester dengan LPKA. Adapun prediksi interaksi polyester dengan tanah pasir melalui gugus polar yang terdapat pada partikel pasir dan matriks polyester dapat diprediksikan seperti gambar dibawah ini.

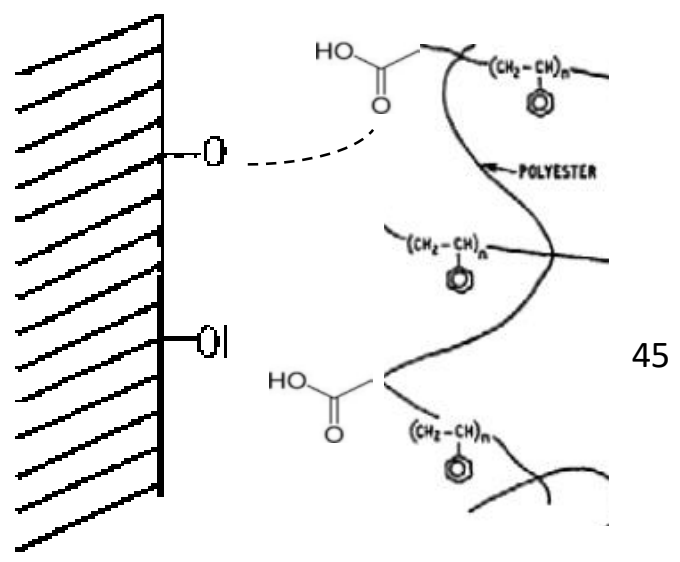




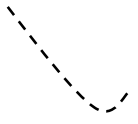

Gambar 3. Tanah Pasir berinteraksi dg poliester

Penelitian ini dilakukan daam skala laboratorium, meliputi pemuatan soil stabilizer dan penggunaannya sebagai perekat material jalan.

Pembuatan Lateks Poliester.

Tabel 1. Komposisi lateks Polyester, Lateks pekat karet alam dan SLS 20\%

$\begin{array}{cccc}\text { No } & \begin{array}{c}\text { Lateks } \\ \text { Polyester } \\ (\mathbf{m l})\end{array} & \begin{array}{c}\text { LP KA } \\ (\mathbf{m l})\end{array} & \begin{array}{c}\text { SLS } \\ \mathbf{2 0 \%} \\ (\mathbf{m l})\end{array} \\ 1 & 90 & 10 & 10 \\ 2 & 70 & 30 & 10 \\ 3 & 50 & 50 & 10 \\ 4 & 30 & 70 & 10 \\ 5 & 10 & 90 & 10\end{array}$

Tabel 2. Komposisi agregat pasir dan Soil Stabilizer.

$\begin{array}{ccc}\text { No } & \begin{array}{c}\text { Agregat } \\ \text { Tanah Pasir } \\ (\mathbf{g r})\end{array} & \begin{array}{c}\text { Soil Stabilizer } \% \\ (\mathbf{m l})\end{array} \\ & 200 & 5 \%=10 \mathrm{ml} \\ 1 & 200 & 10 \%=20 \mathrm{ml} \\ 2 & 200 & 15 \%=30 \mathrm{ml} \\ 3 & 200 & 20 \%=40 \mathrm{ml} \\ 4 & 200 & 25 \%=50 \mathrm{ml} \\ 5 & 200 & 30 \%=60 \mathrm{ml} \\ 6 & 200 & 35 \%=70 \mathrm{ml}\end{array}$

HASIL DAN PEMBAHASAN.

Pembuatan Soil Stabilizer
Soil stabilizer dibuat melalui pencampuran lateks polimer (polyester) dengan lateks pekat karet alam (LPKA). Hasil pencampuran lateks polyester dengan LPKA pada berbagai ratio menggunakan emulsifier SLS 20\% disebut soil stabilizer termoset (SSTS). Soil stabilizer yang dihasilkan dianalisis secara visual dan data hasil pengamatan seperti tabel berikut :

Table 3. Hasil pengamatan visual terhadap soil stabilizer termoset (SSTS).

$\begin{array}{llcll}\text { No } & \text { PE/ } & \begin{array}{r}\text { SLS } \\ \mathbf{2 0 \%} \\ \text { LPKA }\end{array} & \begin{array}{c}\text { Warna } \\ (\mathbf{m l})\end{array} & \text { Keterangan } \\ 1 & 90: 10 & 10 & \text { Putih susu } & \text { Homogen } \\ 2 & 70: 30 & 10 & \text { Putih susu } & \text { Menggumpal } \\ 3 & 50: 50 & 10 & \text { Putih susu } & \text { Menggumpal } \\ 4 & 30: 70 & 10 & \text { Putih susu } & \text { Menggumpal } \\ 5 & 10: 90 & 10 & \text { Putih susu } & \text { Menggumpal } \\ & & & & \end{array}$

\section{Soil Stabilizer sebagai Perekat Tanah Pasir}

Pengaruh soil stabilizer sebagai perekat (soil binder) agregat tanah pasir terhadap sifat mekanis, daya serap air, sifat termal dan morfologi permukaan sampel terlihat pada data-data berikut. Dari hasil uji mekanis secara umum SSTS dapat memperbaiki sifat mekanis tanah pasir. Berikut adalah data hasil uji mekanis terhadap sampel. 
bahan soil stabilizer yakni poliester (Samer Vyes, 2011).

\section{Analisis Kuat Lentur}

Keteguhan lentur dan modulus elastisitas lentur merupakan syarat mutu material struktural menurut Standar Nasional Indonesia (SNI 03-2105-2006). Hubungan antara penambahan soil satabilizer terhadap kuat lentur dapat dilihat pada gambar 4. Peningkatan jumlah SSTS dapat meningkatkan kekuatan lentur sampel.

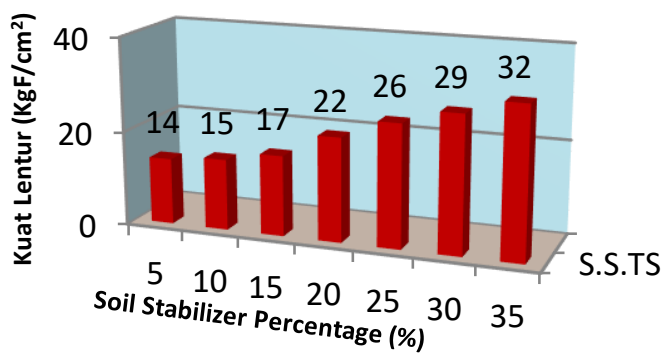

Gambar 4. Hubungan \% soil stabilizer dengan kuat lentur sampel.

Penambahan SSTS juga meningkatkan kuat lentur lentur sampel pada penambahan $5 \%$ - 35\% yaitu $14-31$ $\mathrm{kgf} / \mathrm{cm}^{2}$, hal ini disebabkan polyester merupakan perekat yang baik dan juga karena adanya pembentukan ikatan antara partikel tanah pasir dengan ujung polar

\subsubsection{Analisis Kuat Tekan}

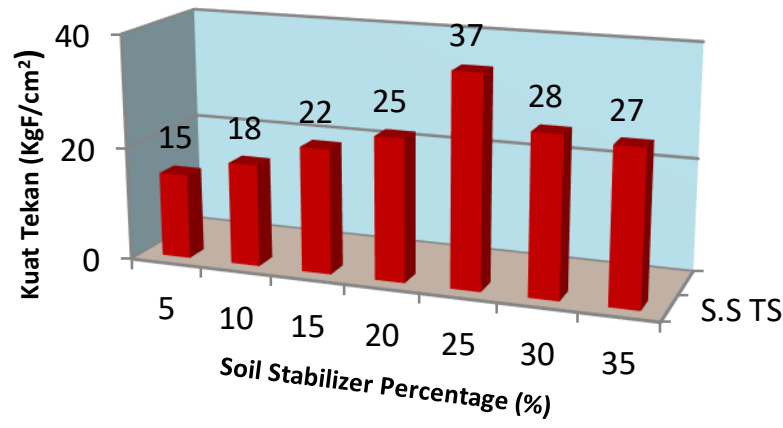

Gambar 5. Hubungan \% soil stabilizer dengan kuat tekan sampel.

Gambar 5 menunjukkan penambahan SSTS pada tanah pasir dapat meningkatkan kuat tekan dari 5\% - 25\% dengan nilai kuat tekan yakni $15-37,3 \mathrm{kgf} / \mathrm{cm}^{2}$. Pada $25 \%$ penambahan SSTS nilai kuat tekan mencapai 3,6 MPa. Kuat tekan komposit hasil campuran agregat tanah pasir dengan SSTS ini sudah memenuhi standar SNI 036883-2002 yakni kuat tekan tanah yang distabilkan harus memiliki kuat tekan 2,1 2,8 MPa. Sementara kuat tekan tanah pasir yang distabilkan dengan SSTP adalah 6,3 MPa dan dengan SSTS adalah 3,6 MPa. Hal ini terjadi karena pori-pori antar agregat 
tanah pasir telah terisi oleh SSTS dan juga akibat adanya gaya adhesi antara partikel agregat dengan soil stabilizer. Disamping itu juga karena adanya pembentukan ikatan kimia antara partikel tanah pasir dan gugus polar poliester pada SSTS. Adanya ikatan kimia ini dapat meningkatkan sifat mekanis sampel (Samer Vyes, 2011). Secara umum penambahan soil stabilizer hingga jumlah tertentu dapat meningkatkan sifat mekanis sampel. Namun pada penambahan pada jumlah yang lebih besar, peningkatan sifat mekanis kurang signifikan (Ali Reza Zandieh et al, 2010).

\section{Analisis Daya Serap Air}

Pasir pada umumnya memiliki daya serap air yang tinggi, hal ini disebabkan karena pasir memiliki porousitas yang tinggi, penambahan soil stabilizer dapat mengisi pori-pori antar partikel pasir dan mengikat partikel tanah pasir. Ikatan kimia yang terjadi yaitu antara partikel tanah pasir yang mengandung $\mathrm{SiO}_{2}$ dan soil stabilizer memiliki gugus polar sehingga dapat mengurangi daya serap sampel terhadap air.

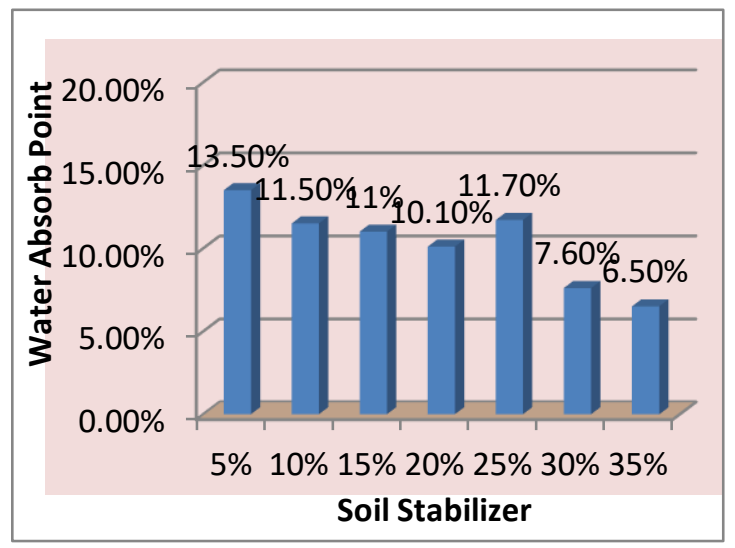

Gambar 6. Penharuh penmbahan soil stabilizer dengan daya serap air

Dari gambar 6 terlihat bahwa daya serap air berkurang seiring dengan peningkatan jumlah soil stabilizer, hal ini karena partikel tanah pasir sangat porous dan bersifat polar yang memiliki affinitas yang besar terhadap air. Dengan adanya soil stabilizer akan mengisi poro-pori tanah pasir dan membentuk ikatan kimia yang dapat mengurangi gugus polar partikel tanah pasir. Hal ini tentu akan mengurangi daya serap sampel terhadap air. Daya serap air sampel menggunakan SSTS minimal adalah $6,56 \%$ pada penambahan soil stabilizer $35 \%$. Soil stabilizer merupakan bahan yang tahan terhadap air (water resistant), sehingga semakin meningkat persentase penambahan SSTS dapat menurunkan daya serap air sampel. Nilai daya serap air tanah pasir yang telah distabilkan dengan SSTS ini hampir memenuhi standar SNI-03 1969 - 1990. Diketahui bahwa nilai daya serap pada tanah yang distabilkan dengan aspal 
maksimum adalah sebesar 3\% (Rianung, 2007).

\section{Analisis Morfologi Permukaan}

Struktur morfologi permukaan sampel dapat dianalisa menggunakan hasil foto SEM. Berikut adalah hasil foto SEM tanah pasir (gbr. 7a). Dari gambar terlihat bahwa permukaan butiran partikel tanah pasir pada skala $1 \mathrm{~mm}$. Dari gambar terlihat adanya pori-pori antar partikel tanah pasir, pori-pori ini diisi oleh udara.

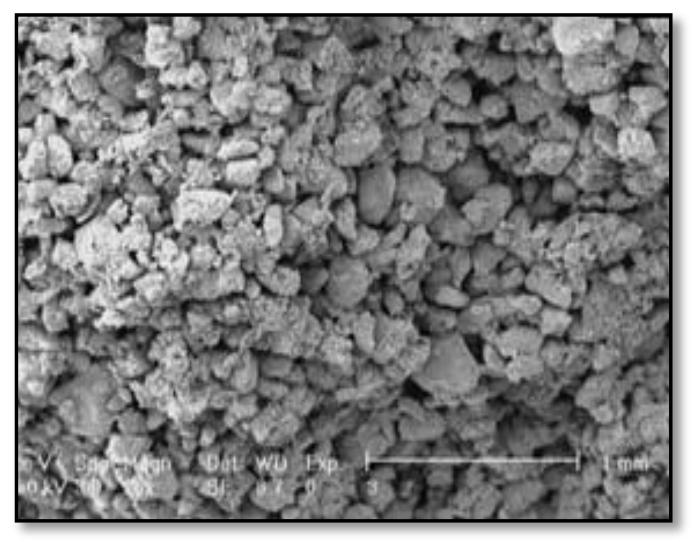

Gambar 7. Hasil Foto SEM Pasir pada perbesaran 2000x.

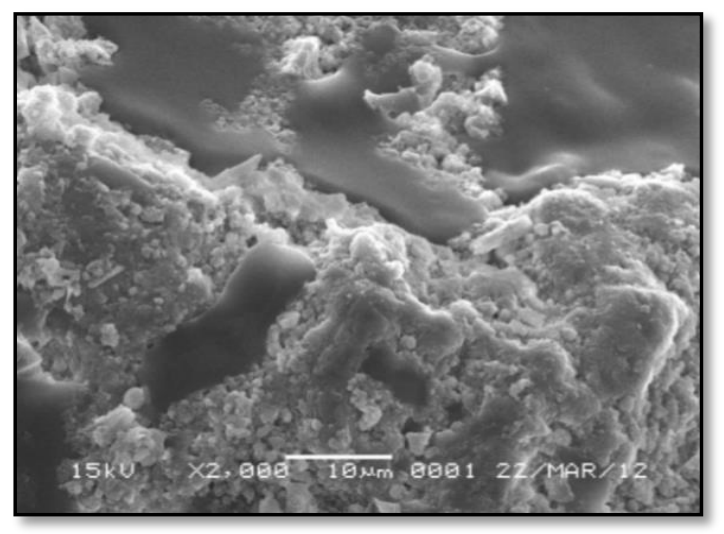

Gambar 8. Hasil Foto SEM Pasir/25\%

SSTS pada perbesaran 2000x.

Pemadatan material ini dapat memperkecil pori-pori antar partikel tetapi adakalanya sebagian udara terkurung dalam pori-pori antar partikel tanah pasir ini. Selain dari pada itu bahwa partikel tanah pasir ini satu sama lain memiliki adhesi dan gaya ikat yang sangat rendah, sehingga memiliki sifat mekanis yang rendah dan daya serap air yang tinggi. Penambahan soil stabilizer diharapkan dapat mengisi dan menggantikan posisi udara yang terkurung di dalam pori-pori antar partikel tanah pasir, dan juga berperan sebagai perekat (soil binder) antara partikel tanah pasir, sehingga dapat meningkatkan sifat mekanis material tanah pasir.

$\begin{array}{rrr}\text { Penambahan } & \text { soil } & \text { stabilizer } \\ \text { memperlihatkan } & \text { adanya } & \text { perubahan }\end{array}$
permukaan yang signifikan. Rongga-rongga tanah pasir yang semula terlihat besar-besar, setelah adanya soil stabilizer rongga rongga tersebut terlihat semakin mengecil, hal ini diperkirakan karena telah diisi oleh soil stabilizer dan adanya interaksi kimia 
antara molekul polyester dengan partikel tanah pasir.

\section{Analisis Termal}

Titik leleh SSTS dan komposit hasil campuran tanah pasir dengan SSTS ditentukan dengan metode differential thermal analysis. Analisis ini dilakukan berujuan untuk mengetahui perubahan sifatsifat material terhadap suhu, yakni suhu leleh, suhu terjadi oksidasi, suhu dekomposisi maupun suhu penguapannya. Pada material teknik perubahan sifat terhadap suhu ini sangat penting sebagai pertimbangan pada teknologi proses

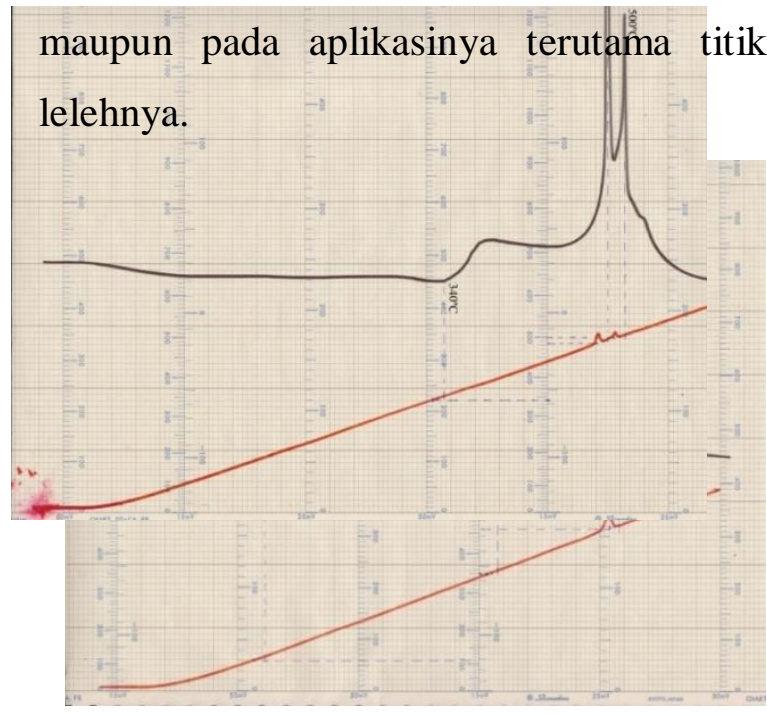

Gambar 8. Termogram DTA SSTS

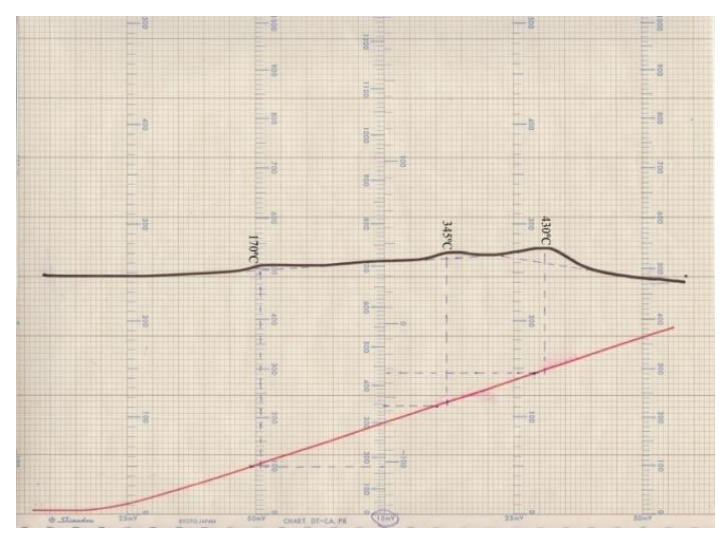


2. Penambahan SSTS pada sampel menyebabkan kenikan sifat mekanis tanah melalui adanya interaksi kimia antara gugus polar polyester pada SSTS dengan agregat tanah pasir

3. Sifat mekanis komposit tanah pasir/SSTS memenuhi standar SNI 036883-2002.

\section{UCAPAN TERIMA KASIH}

Penulis mengucapkan terima kasih kepada pihak DIKTI sebagai penyandang dana pada Hibah Disertasi saya, seluruh staf pengajar S3 Kimia USU Medan, Sekolah Pascasarjana USU, Lembaga Penelitian USU, juga kepada Edi Suratno atas bantuan selama penelitian dan penulisan naskah ini.

\section{DAFTAR PUSTAKA}

Alexandre Marco da Silva, Steven F. Durrant (2010), "Potential Use of Polyacrylamide for Soil Erosion Control in Brazil", Journal of Sustainable Development Vol. 3, No. 4, December: 109 - 117.

Ali Reza Zandieh, S. Shahaboddin Yasrobi (2010), "Study of Factors Affecting the Compressive Strength of Sandy Soil Stabilized with Polymer" Geotech Geol Eng. 28:139-145. DOI 10.1007/s10706009-9287-7.

Balai Penelitian Teknologi Karet Bogor (2011), "Pengenalan Produk Hasil Penelitian dan Teknologi", bptk Bogor.

Billmeyer, F. W.(1971), "Textbook of Polimer Sciense", Second Edition. New York: Jhon Willey and Sons Inc.

Caulfield, D.F, Clemon, C, Jacobson R.E, Rowell, R.M, (2005), “ Wood Plastic Composit", CRC Press,

Chairil Anwar, (2006), "PERKEMBANGAN PASAR DAN PROSPEK AGRIBISNIS KARET DI INDONESIA" Disampaikan pada Lokakarya Budidaya Tanaman Karet, pada tanggal 4-6 September 2006 di Medan, diselenggarakan oleh Balai Penelitian Sungei Putih, Pusat Penelitian Karet.

Christopher Holt Ph.D., P.Eng., Geoblend Canada Corporation, (2010), "Chemical Stabilization of Inherently Weak Subgrade Soils for Road ConstructionApplicability in Canada", Paper Prepared for Presentation at the development of New Technologies for Classification of Materials Session of the 2010 Annual Conference of the Transportation association of Canada Halifax, Nova Scotia.

Jin Liu, Bin Shi, Hongtao Jiang, He Huang, Gonghui Wang, Toshitaka Kamai, 
"Research on the stabilization treatment of clay slope topsoil by organic polymer soil stabilizer", ScienceDirect Engineering Geology 117 (2011) 114-120.

K. Moto, V. Julian, Syamsudin, T. A. Wiradi dan S. R. Wijaya (2004), "Pembuatan Polimer Lateks Emulsi Untuk Peningkatan CBR Tanah SubGrade Pada Konstruksi Jalan” J. MAKARA, TEKNOLOGI, VOL. 8, NO. 2, AGUSTUS: 55-60.

Management Practices Manual, Temporary Erision Management EC-8 SOIL BINDER, .............. diakses pada Agustus 2011.

NICNAS (2007), "SODIUM LAURYL SULFATE" Existing Chemical Information Sheet CAS No: 15121-3.

Rianung, S. (2007), "Kajian Laboratorium Pengaruh Bahan Tambah Gondorukem pada Aspalth Concret-Binder Course (AC-BC) terhadap nilai Prepertis Marshall dan Durabilitas", Semarang.

Roger B., (2000), "Soil Stabilizers On Universally Accessible Trails", Mechanical Engineering Technician USDA Forest Service San Dimas Technology and Development Center, San Dimas, California.

Sachin Waigaonkar, B J C Babu \& Amit Rajput (2011), "Curing studies of unsaturated polyester resin used in FRP products" National Symposium on Polymeric Materials 13-14 December, Subang Jaya, Malaysia. Indian Journal of Engineering \& Materials Sciences Vol. 18, February 2011, pp. 31-39

Sameer Vyas, Neelam Phougat, Murari Ratnam (2011), "Stabilization of Dispersive Soil by Blending Polymers", International Journal of Earth Sciences and Engineering ISSN 0974-5904, Volume 04, No 06 SPL, pp 52-54.

Santoni RL, Tinggle JS, Webster SL (2003), "Stabilization of silty sand with non-traditional additives, transportation research record 1787", TRB, national research council, Washington, DC, pp 3341.

Shackelford J. F.,1996, " The mechanical properties composite", Acta. Metall. Mater, 40.

Wu Dong Qing \& Tan Poi Cheong (2008), "Chemilink Stabilization Technologies for Roads and Airfields ",Chemilink Technologies Group, Singapore www.chemilink.com.sg. Seminar on Soil Sub-grade Stabilization Public Works Department (JKR) of Malaysia \& Road Engineering Association of Malaysia 15 July 2008, Legend Hotel, Kuala Lumpur, Malaysia, Page 1 of 34. 